\title{
O ensino de História na perspectiva da diversidade sexual e de gênero: memórias e práticas docentes
}

\section{History teaching from the perspective of sexual and gender diversity: memories and teaching practices}

\author{
Regina Celi Frechiane Bitte ${ }^{1 *}$, Laylla Corrêa Teixeira Vervloet ${ }^{2}$
}

\begin{abstract}
RESUMO
Este artigo objetiva desenvolver reflexões acerca das potencialidades de um ensino de História que valorize a cultura escolar e que dialogue com conhecimentos acadêmicos e sociais, contribuindo para a formação de um protagonismo juvenil, em defesa da diversidade sexual e de gênero. Para tanto, apoia-se na abordagem metodológica da pesquisa com a História Oral, buscando socializar as memórias e narrativas de docentes atuantes na região metropolitana da Grande Vitória que trabalham a diversidade sexual e de gênero nas aulas de História da Educação Básica. A partir das narrativas dos professores, e em diálogo com a fundamentação teórica acerca da temática, realizou-se uma análise dessas práticas e propõem-se elementos que auxiliem na construção de uma identidade, em defesa da diferença e protagonismo juvenil.
\end{abstract}

Palavras-chave: Diversidade sexual e de gênero; Ensino de História; Narrativas.

\section{ABSTRACT}

This article aims to develop reflections on the potential of teaching History that values school culture and dialogues with academic and social knowledge, contributing to the formation of youth protagonism in defense of sexual and gender diversity. Therefore, it is supported by the methodological approach of research with Oral History, seeking to socialize the memories and narratives of teachers who work in the metropolitan region of Grande Vitória and work on sexual and gender diversity in Basic Education History classes. Based on the teachers' narratives, and in dialogue with the theoretical foundations on the subject, an analysis of these practices was carried out and elements were proposed that help in the construction of an identity in defense of difference and youth protagonism.

Keywords: Sexual and gender diversity; History teaching; Narratives.

\footnotetext{
${ }^{1}$ Universidade Federal do Espírito Santo

*E-mail: reginabitte@yahoo.com.br

${ }^{2}$ Rede Estadual de Ensino do Espírito Santo
} 


\section{INTRODUÇÃO}

Quando pensamos no contexto escolar, nos defrontamos com um cenário que tende a homogeneizar comportamentos. Sujeitos pertencentes ao grupo LGBTQI+ foram e são segregados por meio de práticas e de padrões de normalidade referenciados pelo princípio de grupos dominantes. Não obstante, ainda é grande a prevalência de atitudes discriminatórias e implicitamente excludentes nas relações que se estabelecem no interior das escolas de Educação Básica. Em detrimento dos direitos humanos e das práticas de inclusão, observa-se ainda a permanência de prática de preconceito, discriminação e falta de respeito aos direitos de tais grupos.

Apoiando-nos em Paulo Freire, podemos entender como esse processo de exclusão ocorre dentro das escolas, visto que, em sociedades cuja dinâmica estrutural conduz à dominação de consciências, "a pedagogia dominante é a pedagogia das classes dominantes" (2005, p.7). Sendo assim, uma escola com uma pedagogia opressora não pode, contraditoriamente, servir à libertação do oprimido. Portanto, com essa política opressora não podemos construir uma escola inclusiva.

A partir desses conflitos e dessas relações de poder, Cruz (2012) argumenta: as pessoas que não se submetem aos padrões do que é ser homem e mulher, com orientações sexuais ditas como normais, ao olhar dos padrões sociais dominantes, são, geralmente, expostas à violação de seus direitos, por meio de agressões e todo tipo de discriminação, nas escolas. Ao contrário, segundo a autora,

acima de tudo, a escola tem a tarefa de ensinar os alunos a compartilhar os saberes, os sentidos diferentes das coisas, as emoções, a discutir, a trocar pontos de vista. Em tese, a escola é o lugar em que todos os alunos devem ter as mesmas oportunidades, mas com estratégias de aprendizagens diferentes [...] (CRUZ, 2012, p.15).

Como isso não ocorre, a diversidade nas escolas transforma-se em desigualdade, de acordo com Fante (2005):

\footnotetext{
A intolerância, a ausência de parâmetros que orientem a convivência pacífica e a falta de habilidade para resolver os conflitos são algumas das principais dificuldades detectadas no ambiente escolar. Atualmente, a matéria mais difícil da escola não é a matemática ou a biologia; a convivência, para muitos alunos e de todas as séries, talvez seja a matéria mais difícil de ser aprendida (FANTE, 2005, p.15).
}

É importante lembrar que, entre as atribuições da escola, estaria a de proporcionar ao aluno um ambiente que priorize a equidade e o respeito à diversidade, contribuindo, assim, para formar seres humanos com maior capacidade de empatia com os outros, desenvolvendo um espírito de coletividade.

Nessa direção, o ensino de História pode ser elemento fundamental para que os indivíduos compreendam as relações humanas através do tempo, contribuindo com a função de desenvolver 
e formar a consciência histórica nos sujeitos. Porém, a consciência histórica não se limita somente à ideia de conhecer e entender extensamente as experiências vivenciadas no passado. Mais do que isso, a consciência histórica articula presente, passado e futuro, e faz com que o sujeito compreenda a realidade que o cerca:

Portanto, a consciência histórica tem uma "função prática" de dar identidade aos sujeitos e fornecer à realidade em que eles vivem uma dimensão temporal, uma orientação que pode guiar a ação, intencionalmente, por meio da mediação da memória histórica (SCHIMIDT; GARCIA, 2005, p.301).

Mas, em meio às reflexões e inquietações sobre as concepções de diversidade sexual e de gênero, e às contribuições do ensino de História, surgem algumas indagações: como o ensino de História pode trabalhar a diversidade sexual e a identidade de gênero na escola? Como o ensino de História pode contribuir para o desenvolvimento de um protagonismo juvenil, em adolescentes da educação básica, em busca da defesa do direito à diversidade sexual e de gênero? De que forma podemos desconstruir essa cultura de intolerância e violência que segrega grupos no ambiente escolar? Como incentivar alunos e alunas a conhecerem e a valorizarem a equidade de gênero?

Visando a buscar respostas possíveis para os questionamentos acima, o presente artigo tem como objetivo desenvolver reflexões acerca das potencialidades de um ensino de História que valorize a cultura escolar e que dialogue com conhecimentos acadêmicos e sociais, contribuindo para a formação de um protagonismo juvenil, em defesa da diversidade sexual e de gênero. Para tanto, apoiado na História Oral, busca socializar as memórias e narrativas de docentes que atuam na região Metropolitana da Grande Vitória (Cariacica, Serra, Viana, Fundão, Guarapari, Vila Velha e Vitória), relacionadas ao trabalho da diversidade sexual e de gênero nas aulas de História. Em consonância com a abordagem de pesquisa da História Oral, os procedimentos adotados incluíram rastreamento bibliográfico, que norteou a importância do ensino de História para a (des)construção de identidades estereotipadas, em busca do direito à diversidade, e a realização de entrevistas semiestruturadas com os docentes eleitos como sujeitos da pesquisa: professores de História atuantes na Educação Básica que, em conformidade com a abordagem metodológica da pesquisa, concordaram em ser identificados, não sendo necessário, portanto, recorrer-se aos critérios de invisibilidade dos participantes.

Sendo assim, priorizou-se a metodologia da História Oral. A esse respeito, Delgado (2006) ressalta que:

\footnotetext{
A História Oral é um procedimento metodológico que busca, pela construção de fontes e documentos, registrar, através de narrativas induzidas e estimuladas, testemunhos, versões e interpretações sobre a História e suas múltiplas dimensões: factuais, temporais, espaciais, conflituosas, consensuais (DELGADO, 2006, p.15).
}

Trata-se, portanto, de uma metodologia de pesquisa que permite e aguça nossa escuta em relação aos excluídos, possibilita documentar o não documentado e faz, assim, do professor o 
sujeito da pesquisa. Como metodologia de pesquisa, os pressupostos da História Oral propiciam a elaboração de registros, documentando experiências, saberes e práticas de professores sobre suas vivências. A esse respeito, conclui Delgado (2006):

Portanto, a História Oral é um procedimento, um meio, um caminho para a produção do conhecimento histórico. Traz em si um duplo ensinamento: sobre a época enfocada pelo depoimento - o tempo passado, e sobre a época na qual o depoimento foi produzido - o tempo presente. Trata-se, portanto, de uma produção especializada de documentos e fontes, realizada com interferência do historiador e na qual se cruzam intersubjetividades (DELGADO, 2006, p.16).

Além dessas contribuições, a autora revela outras potencialidades dessa abordagem, como contribuir com novos campos e temas de pesquisa, subsidiar novas hipóteses e versões sobre processos já conhecidos, recuperar memórias locais, regionais, étnicas, de gênero e nacionais, sob diferentes óticas e versões, entre outras, pois as narrativas por meio da memória vão contribuir para a constituição do documento final, a fonte histórica (DELGADO, 2006, p.17). Visando a estimular as memórias e narrativas docentes, esse estudo se apoiará numa das tendências da História Oral que é a História Oral temática³

Pensando no cenário de tensão e violência que vive a escola quando se trata do assunto diversidade sexual e de gênero, justifica-se a realização de estudos e socialização de reflexões que contribuam para que essa temática seja mais discutida nas práticas educativas dentro do ambiente escolar. Esse estudo se propõe a ouvir os professores de História em relação aos seus saberes e fazeres que desvelem truques e estratagemas para debater a temática proposta em sala de aula, debater sobre identidade e diversidade, instigar o protagonismo dos jovens, em busca de seus direitos e deveres na comunidade escolar.

\section{CULTURA ESCOLAR ENTRE O "NÃO SABER" E O "NÃO PODER"}

Parte-se do pressuposto de que a escola poderia ser o espaço para a promoção da cidadania e do conhecimento. Entretanto, para darmos prosseguimento a essa questão, uma tarefa se faz necessária: analisarmos a concepção de educação na qual estamos inseridos. Louro (1997) faz uma análise histórica da ação da escola em relação à construção das diferenças, ressaltando a responsabilidade desta instituição em separar os sujeitos já em seus primórdios, aqueles que lá estavam daqueles que não tinham acesso, ou, ainda, a separação de grupos em seu interior:

Ela dividiu também, internamente, os que lá estavam, através de múltiplos mecanismos de classificação, ordenamento, hierarquização. A escola que nos foi legada pela sociedade ocidental moderna começou por separar adultos de

\footnotetext{
${ }^{3}$ São narrativas de experiências ou processos específicos vividos ou testemunhados pelos entrevistados que contribuam com a constituição de projetos de pesquisa, dissertação de mestrado ou até mesmo tese de doutorado. Há uma maior objetividade, pois a entrevista será focada na temática estabelecida pelo entrevistador (DELGADO, 2006, p.02).
} 
crianças, católicos de protestantes. Ela também se fez diferente para os ricos e para os pobres e ela imediatamente separou os meninos das meninas (LOURO, 1997, p.57).

Continuando sua análise sobre esse processo, a autora acresce que, lentamente, o direito à educação foi sendo reivindicado por aqueles outrora excluídos. Sendo assim, cabia à educação escolar se reorganizar para receber esses novos grupos. Ela “(...) precisou ser diversa: organização, currículos, prédios, docentes, regulamentos, avaliações iriam, explícita ou implicitamente, 'garantir' - e produzir - as diferenças entre os sujeitos.” (LOURO, 1997, p.57)

Essa diversidade que, historicamente, é permeada por relações de poder e dominação, é acompanhada de tensão e ambiguidade. A partir das análises de Foucault (1979) sobre as relações de poder, compreendemos que:

\begin{abstract}
O poder deve ser analisado como algo que circula, ou melhor, como algo que só funciona em cadeia. Nunca está localizado aqui ou ali, nunca está nas mãos de alguns, nunca é apropriado como uma riqueza ou um bem. O poder funciona e se exerce em rede. Nas suas malhas os indivíduos não só circulam, mas estão sempre em posição de exercer este poder e de sofrer sua ação: nunca são o alvo inerte ou consentido do poder, são sempre centros de transmissão. Em outros termos, o poder não se aplica aos indivíduos, passa por eles (FOUCAULT, 1979, p.183).
\end{abstract}

No que se refere ao "poder" envolto nas questões da sexualidade, Foucault (1979) assevera, em seus estudos, que a identificação do sujeito com a sexualidade se tornou algo debatido e imposto pela intervenção médica. Tornou-se objeto de estudo dos saberes médicos e, a partir do século XIX, surgiu a identificação homossexual. Então, o que antes eram práticas condenadas em algumas sociedades e naturalizadas em outras, passou a caracterizar um "desvio de personalidade".

A sociedade, então, por meio de várias instituições, como escola, igreja e poder público, garantiu que toda e qualquer diferença fosse tratada de forma medicinal, como "desvio de personalidade", reproduzindo e construindo uma educação heteronormativa ${ }^{4}$.

A teoria Queer $^{5}$ discute a formação das identidades de gênero como uma construção social. Isso se estende também para nossas identidades sexuais. Indo mais adiante, Silva (1999) faz reflexões acerca dessa construção social da identidade, a partir da relação com o outro, sendo esta atravessada por significação:

\footnotetext{
4“[...] pode-se compreender o termo heteronormatividade como aquilo que é tomado como parâmetro de normalidade em relação à sexualidade, para designar como norma e como normal a atração e/ou o comportamento sexual entre indivíduos de sexos diferentes" (PETRY; MEYER, 2011, p.196).

${ }^{5}$ A teoria Queer surge, em países como Estados Unidos e Inglaterra, como uma espécie de unificação dos estudos gays e lébicos. Historicamente, o termo queer tem sido utilizado para se referir, de forma depreciativa, às pessoas homossexuais, sobretudo do sexo masculino (SILVA, 1999).
} 


\begin{abstract}
Além disso, a identidade não é uma coisa da natureza; ela é definida num processo de significação: é preciso que, socialmente, lhe seja atribuído um significado. Como um ato social, essa atribuição de significado está, fundamentalmente, sujeita ao poder. Alguns grupos sociais estão em posição de impor seus significados sobre os outros. Não existe identidade sem significação. Não existe significação sem poder (SILVA, 1999, p.106).
\end{abstract}

Dessa maneira, a heterossexualidade depende da definição da homossexualidade. Sendo a heterossexualidade definida como "sexualidade dominante hegemônica", automaticamente a homossexualidade se torna desvio da normalidade (SILVA, 1999, p.106).

Para tentarmos entender como a História pode contribuir nesses debates e na construção de uma cultura de respeito às diferentes identidades, no ambiente escolar, estabelecemos um diálogo com Pesavento que, por sua vez, dialoga com historiadores da Nova História Cultural, que tem como mola mestra, em seus debates, o conceito de cultura entendida "como conjunto de significados partilhados e construídos pelos homens para explicar o mundo" (2004, p.15).

Com a História Cultural, possibilidades se abrem para entender e decifrar o passado, por meio das suas representações, Pasavento aponta que (2004):

\begin{abstract}
As representações construídas sobre o mundo não só se colocam no lugar deste mundo, como fazem com que os homens percebam a realidade e pautem a sua existência. São matrizes geradoras de condutas e práticas sociais, dotadas de força integradora e coesiva, bem como explicativa do real. Indivíduos e grupos dão sentido ao mundo por meio das representações que constroem sobre a realidade (PESAVENTO, 2004, p.39).
\end{abstract}

Será por meio das representações que também entenderemos como o mundo é construído de várias maneiras e, até mesmo, de maneiras contraditórias pelos diferentes grupos, como cita a autora:

Aquele que tem o poder simbólico de dizer e fazer crer sobre o mundo tem o controle da vida social e expressa a supremacia conquistada em uma relação histórica de forças. Implica que esse grupo vai impor a sua maneira de dar a ver o mundo, de estabelecer classificações e divisões, de propor valores e normas, que orientam o gosto e a percepção, que definem limites e autorizam os comportamentos e os papéis sociais (PESAVENTO, 2004, p.41).

Podemos perceber uma renovação metodológica e até mesmo uma releitura das fontes, onde a problematização e a ampliação do objeto de estudo, uma preocupação não só com os fatos, mas também com as permanências e resistências às mudanças, a ampliação das fontes para todo vestígio humano, faz com que a discussão do conhecimento e sua produção se tornem uma atividade social (CIAMPI, 2011, p.55).

Trabalhar a equidade e a diversidade de gênero, no contexto educativo, significa desconstruir as relações de poder presentes na sociedade, possibilitando que as pessoas possam ter acesso a diferentes espaços e que possam viver sua sexualidade ou sua identidade de gênero, livres de qualquer tipo de discriminação. 


\section{ESTRATÉGIAS DO USO DA DIVERSIDADE SEXUAL E DE GÊNERO NO ENSINO DE HISTÓRIA: SABERES E FAZERES DOCENTES}

As questões de gênero e sexualidade têm sido contempladas nos debates, na Associação Nacional de História (ANPUH), no Encontro Nacional de Pesquisadores de Ensino de História (ENPEH) e no Encontro Nacional Perspectivas do Ensino de História, no que se refere ao currículo e ao seu trato em sala de aula. De quais sentidos de gênero e sexualidade a escola tem se apropriado enquanto espaço, e o ensino de História, como prática social?

Gênero e sexualidade são conceitos que vêm sendo estudados e vistos como construções sociais, isto é, construídos historicamente a partir de como as diferentes sociedades se posicionam mediante o tema. Dessa forma, podemos entender gênero e sexualidade de maneira mais dinâmica. Isso porque, se entendermos que o modo como enxergamos as sexualidades e a forma como nós enxergamos mulheres e homens são frutos de construções discursivas, perceberemos que é sempre possível construir uma sociedade com novas possibilidades de identidade e de convívio.

Apesar de a discussão sobre o combate à desigualdade e discriminação nas escolas ser prevista pela Base Nacional Comum Curricular (BNCC), em sua versão ampliada - ensino médio (BRASIL, 2018) $^{6}$, permanece a falta do debate sobre a diversidade sexual e de gênero, principalmente no aspecto ético:

\footnotetext{
Para tanto, os estudantes devem dialogar sobre noções básicas como o respeito, a convivência e o bem comum em situações concretas. A ética pressupõe a avaliação de posturas e a tomada de posição em defesa dos direitos humanos, a identificação do bem comum e o estímulo ao respeito e ao acolhimento às diferenças entre pessoas e povos, tendo em vista a promoção do convívio social e o respeito universal às pessoas, ao bem público e à coletividade (BRASIL, 2018 p.555).
}

Essa temática requer maiores inserções nas propostas curriculares e nas formações de profissionais da educação. A falta ou os poucos debates implicam noções que limitam as concepções de gênero e sexualidade nas escolas e se distanciam das formas de resolver as desigualdades no ambiente escolar. A esse respeito, aduz Pinsky (2015):

As concepções de gênero tanto são produtos das relações sociais quanto produzem e atuam na construção destas relações, determinando experiências, influindo nas condutas e práticas e estruturando expectativas (PINSKY, 2015, p.34).

\footnotetext{
${ }^{6}$ A Base Nacional Comum Curricular (BNCC) é um documento de caráter normativo que define o conjunto orgânico e progressivo de aprendizagens essenciais que todos os alunos devem desenvolver ao longo das etapas e modalidades da Educação Básica (BRASIL, 2018).
} 
O processo histórico que legitima as concepções sobre as normatizações e padrões de comportamento entre homens e mulheres acarreta, ainda, na sociedade, diferentes estigmas para aqueles que não se enquadram no modelo patriarcal. Portanto, a ideia de heteronormatividade retira a singularidade desses sujeitos, ao representá-los como alguém que "deformou", "perdeu" ou "minimizou" o seu gênero original (LOURO, 2009).

Pensando nesse contexto, a disciplina de História pode (des/re)construir e debater como responsável a lógica sexista que vivemos no ambiente escolar, através da problematização das questões de diversidade sexual e de gênero. Pode, sim, refletir sobre alternativas que possibilitem a desconstrução de uma sociedade heteronormativa e que ampliem o debate, estimulando as críticas aos estereótipos apresentados nos diferentes veículos de comunicação e denunciando as formas como os discursos acabam segregando cada vez mais grupos que não se adequam a essa realidade.

Será por meio da análise histórica das violências sofridas, e da negação dessa violência, que o ensino de História, com vistas à equidade social, poderá contribuir com a negação dos discursos de ódio e a discriminação no ambiente escolar. Nesse sentido, “(...) capacitar os estudantes para perceber a historicidade de concepções, mentalidades, práticas e formas de relações sociais é justamente uma das principais funções das aulas de História" (PINSKY, 2015, p.32).

Entendemos, juntamente com Pinsky, que o objetivo do ensino de História é construir, com os alunos, conhecimentos que lhes permitam conhecer, criticar e transformar a realidade em que vivem, e também se tornar responsáveis por mediar e impedir a propagação da violência na desconstrução do sexismo e exclusão:

Ao observar que as ideias a respeito do que é "ser homem" e "ser mulher", os
papeis considerados femininos e masculinos ou a condição das mulheres, por
exemplo, foram se transformando ao longo da história (como e por que), os
alunos passam a ter uma visão mais crítica de suas próprias concepções, bem
como das regras sociais e verdades apresentadas como absolutas e definitivas
no que diz respeito às relações de gênero (PINSKY, 2015, p.32-33).

Pensando nas possibilidades que o ensino de História nos proporciona para trabalhar essa temática, esse estudo foi em busca de saberes e fazeres de professores da Educação Básica do munícipio da Serra, no Espírito Santo, para resgatar suas memórias, como forma de entender, valorizar e divulgar práticas que contribuam para a construção de um ambiente escolar que promova a equidade e a justiça social.

Dessa forma, trazemos as memórias dos professores, como sujeitos da história do cotidiano escolar. Rodrigues (2011) salienta que a reflexão e a construção das identidades profissionais dos professores integram experiências, trajetórias e desejos às possibilidades de ações transformadoras dos docentes: 
A análise sobre a influência de vivências anteriores dos professores em suas práticas pedagógicas pode ser considerada como contribuições importantes para a compreensão de suas posturas profissionais. Contudo, é imprescindível que o professor tenha consciência da origem de sua própria prática, a relação com o ensino e com seus alunos. Esse conhecimento possibilita ao professor a oportunidade de superar crises, reformular a postura pedagógica, as crenças em relação à matéria que leciona, as formas que utiliza para avaliar seus alunos e outros aspectos que possam resgatar a imagem pessoal do bom professor (RODRIGUES, 2011, p.1108).

Assim, as narrativas são muito mais do que simples descrições de suas vidas, pois, ao repensarem suas histórias, os professores refletem sobre quem são, reconstruindo continuamente significações acerca de si e de seu trabalho, e compartilhando, com os outros, experiências vividas no ambiente profissional.

Em entrevista com professores de escolas de Ensino Médio do município da Serra - ES, pudemos notar práticas destinadas a trabalhar um conteúdo de História menos sexista, como afirma a professora Juliana Quintela:

Como eu trabalho isso? Não é tipo, separado, por exemplo, tal conteúdo vai falar dessa questão! É junto! Ensinando mesmo a questão, às vezes fica meio implícito, por exemplo: se eu estou falando de Era Vargas e vem o voto feminino, aí a gente vai debater e questionar toda essa questão, Vargas era muito bonzinho? Então você faz toda uma crítica em cima daquilo. Quando você fala de Revolução industrial, a mulher já receber bem menos. A gente vai falando dessas questões todas. Quando você fala de uma monarquia, igual eu estava falando de Revolução Inglesa e a Elizabeth não casa, você problematiza o que é o casamento, como era o casamento pra mulher, uma família real naquele período, de outras classes também, mas na família real o casamento era um acordo, questão de negócios. Então, assim, a gente vai problematizando e trazendo para as questões atuais (QUINTELA, 2019).

Portanto, é a partir das relações sociais, da relação com o outro, que podemos perceber como as "experiências e as condições materiais de existência, por sua vez, influem na constituição do pensamento - as pessoas passam a agir de acordo com os significados construídos" (PINSKY, 2015, p.34).

As narrativas da professora Juliana Quintela também revelam que as problematizações nem sempre são propostas pelos professores ou professoras. De acordo com ela, um grupo de alunas a abordou e pediu uma intervenção dela para que fosse trabalhado o dia Internacional da Mulher, com enfoque na desconstrução do machismo e no debate sobre a violência que as mulheres daquela comunidade escolar sofrem. Então, com a ajuda de outros professores, ela realizou um projeto que envolvia toda a escola:

[...] eu preparei uma fala que seria em cima desse debate do que é o dia da mulher e que não é dia de dar parabéns, dar florzinha e bombom. Grupos de alunos dos terceiros anos que ficaram mais ativos. Eles pegaram músicas que traziam letras machistas e reescreveram com uma versão como a resposta, mostrando que aquela música tinha letra machista e a gente canta todo dia e não percebe. E iniciamos isso tudo de uma forma bem pesada, que foi assim: eram 6 alunas que estavam de preto com hematomas e a gente desenhou, 
maquiou e cada uma segurava um objeto na mão do dia a dia como uma cadeira, uma caneta, um capacete coisas banais. Enquanto elas ficavam paradas com aqueles objetos eu ia lendo uma história real de agressão que uma mulher sofreu com aquele objeto. E aí a gente foi problematizando em conjunto com a escola e eu fazendo perguntas e eles respondendo. E isso durante essa semana que a gente organizou. [...] O que veio de menina conversar e querer entender essas questões sobre a mulher, e falar que estava namorando ali na escola e o menino forçou relação sexual, queria e ela não queria ainda não estava pronta, e várias coisas foram chegando [...] (QUINTELA, 2019).

Podemos observar, por meio de seus relatos, que, com essa experiência, a docente percebeu a necessidade de desenvolver mais projetos sobre a temática e se preparar para desenrolar algo maior, no sentido de desconstruir o sexismo.

De forma semelhante, a narrativa da professora Dayana Tonon nos fornece pistas sobre a importância de abordar a temática com os alunos, partindo da sondagem e mesmo do diagnóstico da realidade dos estudantes. Segundo sua narrativa, as relações de confiança entre ela e seus alunos propiciam e facilitam seu trabalho.

Eu tinha um primeiro momento com eles. Momento de expor dados a respeito
de violência contra mulher no Brasil, violência simbólica, violência física,
violência sexual, falava sobre todos os tipos de violência em sala. Levava
dados, levava gráficos, explicava que nada daquilo ali eu estava falando por
falar, eu tinha tudo documentado. E aí a gente fazia um debate, todas as turmas
participavam, meninos e meninas participavam. É um debate que rendia
demais, porque nesse momento, quando eu expunha tudo, brotavam coisas de
onde eu jamais esperava que aparecessem. Fiquei carregada demais nisso.
Porque vieram meninas me contar que sofreram assédio dentro de casa, e
vieram meninos me contar que sofreram violência sexual do tio, do padrasto
que nunca tinham contado. Eu vinha recebendo alunos e alunas contando o que
acontecia em sala de aula, o que o professor fazia (TONON, 2019).

A entrevistada, narra que a partir de casos de violência contra a mulher que estavam em evidência na mídia, no ano de 2016, resolveu escrever um projeto para trabalhar com os alunos. Antes mesmo de colocar o projeto em prática, um grupo de alunas surpreendeu a escola com a tentativa de lutar contra as violências que aconteciam dentro do ambiente escolar:

[...] umas meninas de uma das unidades fizeram uma movimentação sem saber que eu já tinha um projeto para acontecer. Elas fizeram a movimentação justamente porque elas estavam incomodadas com a situação das cantadas de professor, com a situação de assédio, das piadinhas em sala de aula. Então, elas imprimiram várias imagens de falas e imagens feministas empoderadas e fizeram uma colagem imensa na porta do banheiro feminino, por dentro e por fora, e ninguém sabia quem tinha feito. Fizeram já no final de um turno. No outro dia de manhã, a escola já tinha arrancado tudo (TONON, 2019).

Segundo a narrativa da professora, a escola, ao invés de acolher e transformar esse protesto em construção de conhecimento por meio do protagonismo, o ignorou. Em relação ao seu projeto, que tomou proporções gigantescas, a opção da escola foi de demiti-la.

Após a escuta atenta dos professores, pudemos inferir a necessidade do debate sobre a diversidade sexual e de gênero não só em sala, mas em todo o ambiente escolar. Essa percepção 
também é compartilhada pelo professor Cristiano Neto, cujas narrativas ratificam as experiências das outras professoras e reafirmam que o discurso machista também está presente na comunidade escolar em que trabalha:

No início do ano, no mês de março, justamente devido ao dia da mulher, nós costumamos fazer projetos direcionados ao gênero, especificamente à relação homem e mulher, inclusão também da discussão LGBT, embora o LGBT seja ainda mais resistente para os alunos do que a inclusão da mulher. Eles já entenderam que a mulher deve, por todas as circunstâncias, ser incluída no discurso histórico. Mas a questão LGBT ainda é uma patinação, não é ainda tão forte. Embora a gente tenha alunos empoderados LGBTs aqui na escola, e meninas também empoderadíssimas, aqui especificamente, por se tratar também de uma realidade social periférica, a gente percebe que ainda há uma resistência grande a estudos de LGBTs (NETO, 2019).

Nosso entrevistado continua destacando a forma como trabalha a questão de gênero dando ênfase às conquistas femininas ao longo da História:

Então eu falo, normalmente faço um traço histórico das conquistas femininas ao longo da História, tentando mostrar para eles que o espaço atualmente ocupado pelas mulheres não se trata de um presente gratuito. Não foi dado a elas. Foi uma conquista, conquista delas, não é uma conquista do homem, conquista da mulher. Se ela em 1934 pode votar, se depois veio a pílula anticoncepcional, então a lei Maria da Penha, a lei do feminicídio..., eu tento mostrar para eles, de alguma maneira, que isso é uma conquista exclusivamente feminina, da luta feminina, de mulheres que lá atrás foram às ruas pra isso. Então, normalmente eu descrevo com muita profundidade as leis, passo vídeos para eles sobre a inclusão da mulher no mercado de trabalho, de quanto isso ainda é um obstáculo, em 2019, trabalho com eles também ( NETO, 2019).

As narrativas dos professores nos remetem às indagações do início de nosso tópico em relação à formação dos professores, o que nos leva a pensar que a questão da sexualidade e de gênero tem sido tangenciada. A não compreensão sobre a dimensão sociocultural da sexualidade e de gênero abre portas e janelas que desvelam fortes gargalos na formação de professores e, por consequência, na sua atuação na Educação Básica. Educadores passam a reproduzir seus valores e atitudes sobre a sexualidade no ambiente escolar sem um embasamento teórico, como identificou a professora Quintela:

É aquele lance que a gente vê muito. Todo mundo fala muito bonito, tipo assim "é tem que ter isso, machismo não", mas ninguém consegue refletir na sua prática, que aquela coisinha mínima que você falou foi machista, que aquela coisinha mínima que você falou foi homofóbica. Então, as pessoas continuam reproduzindo e aí falam muitas coisas clichês e superficiais e não levam para prática. A autocritica não acontece. Eu acho que o professor ele tem se acomodado, na questão de tocar na própria ferida, são raras as pessoas que tocam na própria ferida no sentido de falar "pô, eu cometo isso". A gente se coloca no pedestal de que não erra, de que sabemos tudo de tudo, então a gente não reflete e não aceita quando alguém fala: "isso que você está falando é machismo"! Quando alguém fala isso, essa pessoa sai de louca e surtada, entendeu? E isso é um problema muito grande. (QUINTELA, 2019). 
São perceptíveis as tentativas de trabalhos e ações desses docentes, agindo na contracultura das violências e que se propõem a produzir outros modos de pensar sobre a escola e de construir relações sociais mais democráticas e respeitosas com a diversidade.

Porém, há um enorme desafio a ser enfrentado, que vem sendo clamado por grupos da comunidade escolar, pela construção de uma nova forma de lidar com as relações dentro desse ambiente, a partir da própria visibilidade do fenômeno: a compreensão dos direitos humanos, a proteção dos direitos de igualdade, a educação para a sexualidade ou para as sexualidades.

\section{CONSIDERAÇÕES FINAIS}

A desigualdade de gênero, ou seja, a desvalorização do feminino em oposição ao masculino é marcada pela violência. Mulheres e LGBTQI+ são alvos de discriminação verbal, simbólica ou física.

A partir da narrativa dos professores, podemos constatar o trabalho no combate ao sexismo, presente no ensino de História. Esses professores contestam e trabalham diuturnamente na desconstrução da História que valoriza somente a figura masculina, excluindo a participação feminina no processo de construção da História. Observamos que a metodologia de ensino, por meio de projetos, contribuiu para a discussão dos temas propostos, sexualidade e gênero, permitindo uma escuta atenta dos alunos, ao externalizarem suas inquietações, angústias e curiosidades em relação às discriminações por eles vivenciadas. Ao término dos trabalhos realizados pelos professores, podemos dizer que os alunos se sentiram empoderados.

As narrativas dos professores também nos permitiram identificar que o fato de os outros professores não abordarem a temática, em suas aulas, ou mesmo em outros espaços escolares, pode advir da falta ou do pouco conhecimento em relação às temáticas da sexualidade e de gênero. Podemos supor que, ao não ter contato com essa temática, seja pela primeira formação ou pela formação continuada, os docentes acabam por não contemplá-la, por desconhecimento ou insegurança.

Portanto, a escola pode contribuir com os debates em relação ao repensar valores culturais e incentivar a desconstrução de visões míopes no que concerne às opções dos sujeitos. Trabalhar ações inclusivas, de respeito ao outro, sinaliza para um bom caminho. E, nesse caminhar, cabe ao ensino de História trabalhar com o estudante a reflexão, que lhe possibilite compreender as diferentes visões sobre sexualidade e gênero inerentes ao processo histórico e de construção do conhecimento. 


\section{REFERÊNCIAS}

BASTIANINI, Marco Antonio Diniz. A Educação e a Diversidade Sexual e de Gênero: uma análise a partir da proposta dos Temas Transversais na perspectiva dos educadores. 154 f. Dissertação (Mestrado em Serviço Social) - Programa de Pós-Graduação em Serviço Social, Universidade Estadual Paulista “Júlio de Mesquita Filho”. Franca, 2017.

BRASIL. Base Nacional Comum Curricular. Brasília: MEC/SEF, 2018

CIAMPI, H. Ensinar História no século XXI: dilemas e propostas. In: Ensino de História: Ensaios sobre questões Teóricas e Práticas. Maringá: Eduem, 2011. p.51-71

CRUZ, M. H. S. Refletindo sobre a diversidade de gênero no campo da educação. Saberes em perspectivas, v. 2, n. 2, jan./abr. 2012.Disponível em:

<https://philpapers.org/rec/CRURSA>. Acesso em: 02 ago. 2019.

DELGADO, L. de A. N. História Oral: memória, tempo e identidades. Belo Horizonte: Autêntica, 2006. p. 15-31.

FANTE, C. Fenômeno bullying: como prevenir a violência nas escolas e educar para a paz.2. ed rev. e ampl. Campinas, SP: Verus Editora, 2005

FOUCAULT, M. História da sexualidade I: A vontade de saber. $12^{\mathrm{a} e d .}$ Rio de Janeiro: Graal, 1997.

FOUCAULT, M. Microfísica do poder. Rio de Janeiro: Graal, 1979.

FREIRE, P. Pedagogia do Oprimido. 48ª ed. Rio de Janeiro: Paz e Terra, 2005.

LOURO, G. L. Gênero, sexualidade e educação: uma perspectiva pós estruturalista. Petrópolis: Vozes, 1997.

LOURO, G. L. Gênero, história e educação: construção e desconstrução. Revista Educação e Realidade, v. 20, n. 2, p.101-132, jun a dez 1995.

MORIN, E. Os sete saberes necessários à educação de futuro. São Paulo: Contexto, 2006.

NETO, C. Entrevista[ago.2019]. Entrevistadora: Laylla Correa Teixeira Vervloet, Serra, 2019.

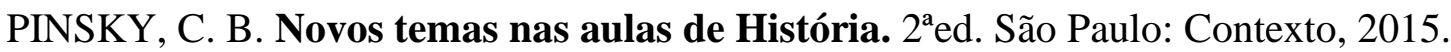

PESAVENTO, S. J. História \& História Cultural. 2aed. Belo Horizonte: Autêntica, 2004.

PETRY, A. R.; MEYER, D. E. E. Transexualidade e heteronormatividade: algumas questões para a pesquisa. Porto Alegre: Textos \& Contextos, 2011. Vol.10, p. 193-198.

QUINTELA, J. Entrevista [set.2019]. Entrevistadora: Laylla Correa Teixeira Vervloet, Serra, 2019. 
SILVA, T. T. da. Documentos de identidade: uma introdução às teorias do currículo. Belo Horizonte: Autêntica, 1999.

TONON, D. Entrevista [set.2019]. Entrevistadora: Laylla Correa Teixeira Vervloet, Serra, 2019.

Recebido em: 08/01/2022

Aprovado em: 10/02/2022

Publicado em: 14/02/2022 